\title{
XXVI. Mr. Blakesley's method of measuring power in transformers
}

\author{
Prof. J. Perry F.R.S.
}

To cite this article: Prof. J. Perry F.R.S. (1891) XXVI. Mr. Blakesley's method of measuring power in transformers, Philosophical Magazine Series 5, 32:195, 185-192, DOI:

$10.1080 / 14786449108621410$

To link to this article: http://dx.doi.org/10.1080/14786449108621410

曲 Published online: 08 May 2009.

Submit your article to this journal $\lceil\pi$

Џ Article views: 2

Q View related articles $\asymp$ 
effective primary volts by effective primary amperes. But when there is magnetic leakage, this rule is wrong. The ratio of $\frac{\mathrm{P}}{\mathrm{W}}$, for example, in the second table is never greater than $\cos 20^{\circ}$. Such experimental results as are at my command confirm my view that

Effective Primary Volts $\times$ Effective Primary Amperes give a result always greater than the true power, even for very great loads; a result to be expected if there is considerable magnetic leakage.

XXVI. Mr. Blakesley's Method of Measuring Power in Transformers. By Prof. J. PkRry, F.R.S.*

$\mathbf{M}^{\mathrm{R}}$

R. BLAKESLEY'S method of measuring the power given to the primary coil of a transformer becomes more important the more it is studied. Mr. Blakesley proved it to be correct if currents followed the simplest periodic law; if there was no magnetic leakage; if magnetic permeability was constant. Any person who has used Fourier's theorem knows that if Mr. Blakesley's rule is right for a sine function, it must be right for any periodic function whatsover; as any periodic function may be expressed in sine functions, and each of these enters into the equations as if it were alonet.

* Communicated by the Physical Society : read May 22, 1891.

+ This assertion was challenged in the discussion. Perhaps I ought to have explained myself more fully. At the time I happened to be working with Fourier's Serios very much, and I lost sight of the facs that what was very evident to me might not be evident to others.

If

and

$$
\begin{aligned}
& x=\Sigma_{1}^{\alpha_{j}}\left(a_{i} \sin i k t+b_{i} \cos i k t\right), \\
& y=\Sigma_{1}^{\infty}\left(\alpha_{i} \sin i k t+\beta_{i} \cos i k t\right),
\end{aligned}
$$

where $k=\frac{2 \pi}{\tau}$ and $\tau$ is the periodic time, then the average value of $x y$ between the limits 0 and $\tau$ is

$$
{ }_{2} \Sigma\left(a_{i} \alpha_{i}+b_{i} \beta_{i}\right)
$$

and does not involve any term such as $a_{i} \alpha_{r}$ or $b_{i} \beta_{r}$; that is, into the expression for the average value each term of the Fourier's Series enters just as if there were no other terms. Nearly all practical Electrical Engineers are in the habit of ignoring calculations which assume that a current is a sine function of the time; they say that such calculations are useless because the current never is a true sine function of the time. I have here given one of many examples which might be given in which a proposition concerning any periodic function need only be proved for one of the Fourier terms of that function. And in all cases, the result of the study of a sine function is at once applicable to any periodic function whatsoever. 
Prof. Ayrton and Mr. Taylor have proved the method to be correct for currents of any periodic law, the permeability varying in any way whatever. But they make the assumption that there is no magnetic leakage.

I believe that it was Dr. Hopkinson who, in his paper read before the Royal Society on March 10th, 1887, first departed from the old-fashioned way of treating mathematically the equations concerning currents in neighbouring coils, and he has been followed by everybody else who has written upon that subject since. Some writers of eminence have given, and incompletely, Hopkinson's investigation, evidently not having seen his paper. In my opinion the ustual method is somewhat misleading. Assuming no eddy currents in the conducting part of a transformer, the equations written in the oldfashioned, and in what I venture to say is the only correct way, become

$$
\left.\begin{array}{l}
\mathrm{V}=\mathrm{RC}+\mathrm{L} \dot{\mathrm{C}}+\mathrm{M}_{\dot{C}^{\prime}} \\
\mathrm{O}=\mathrm{R}^{\prime} \mathrm{C}^{\prime}+\mathrm{M} \dot{\mathrm{C}}+\mathrm{L}^{\prime} \dot{\mathrm{C}}^{\prime}
\end{array}\right\}
$$

Here $\mathrm{V}$ is the voltage at the terminals of the primary circuit, $\mathrm{R}$ its resistance, $\mathrm{C}$ its current, and $\mathrm{L}$ its coefficient of self-induction. $R^{\prime}$ is the resistance of the whole secondary circuit, in which we assume no independent electromotive force; $\mathrm{C}^{\prime}$ is its current, $\mathrm{L}^{\prime}$ is its coefficient of self-induction, and $\mathrm{M}$ is the mutual induction between the two circuits. It may be well to state that, using amperes, volts, and ohms:If $\mathrm{P}$ and $\mathrm{S}$ are the numbers of windings of the primary and secondary respectively; if $a$ is the cross section of the iron in square centimetres, $\lambda$ the average length of the complete iron magnetic circuit, and $\mu$ the permeability (being about 1500 in ordinary transformer working), we may take it that

$$
\begin{aligned}
\mathrm{L} & =\mathrm{P}^{2} \frac{a \mu}{\lambda} \frac{4 \pi}{10}, \\
\mathrm{~L}^{\prime} & =\mathrm{S}^{2} \frac{a \mu}{\lambda} \frac{4 \pi}{10} ;
\end{aligned}
$$

and if there were no magnetic leakage-that is, if all the field due to a primary current through every single winding of the primary passed through every single winding of the secondary, then $\mathrm{M}=\sqrt{\mathrm{LL}^{\prime}}$, or

$$
\mathrm{M}=\mathrm{PS} \frac{a \mu}{\lambda} \frac{4 \pi}{10} \text {. }
$$

But there is always some magnetic leakage, and it fills me with astonishment that so many investigators should assume that a little leakage makes no difference. 
To get an idea of the importance of even a little leakage let us eliminate $\dot{\mathrm{C}}_{1}$ from equations (1) and we have the result

$$
\mathrm{V}=\mathrm{RC}-\mathrm{R}^{\prime} \frac{\mathrm{M}}{\mathrm{L}^{\prime}} \mathrm{C}^{\prime}+\frac{\mathrm{LL^{ \prime } - \mathrm { M } ^ { 2 }}}{\mathrm{L}^{\prime}} \dot{\mathrm{C}} . \quad . \quad . \quad . \quad .
$$

The usual assumption that if LL' only differs by a very little from $\mathrm{M}^{2}$ the error is unimportant, is seen to be inadmissible when we consider how great a value $\dot{\mathrm{C}}$ sometimes may have in comparison with $\mathrm{C}$ or $\mathrm{C}^{\prime}$. Thus, for example, in a transformer with which I have had something to do experimentally, $L=15, L^{\prime}=0 \cdot 15, R=10$, and $M$ is very nearly $1 \cdot 5$; so that (2) becomes

$$
\mathrm{V}=10 \mathrm{C}+10 \mathrm{R}^{\prime} \mathrm{C}^{\prime}+\left(15-\frac{\mathrm{M}^{2}}{\mathrm{~L}^{\prime}}\right) \dot{\mathrm{C}}
$$

Now, to take the very simplest kind of periodic current, and the one for which the above wrong assumption is least wrong, and a frequency of 106 per second-writing, in fact,

we know that

$$
\mathrm{C}=\mathrm{A} \sin 1000 t
$$

$$
\dot{\mathrm{C}}=1000 \mathrm{~A} \cos 1000 t \text {. }
$$

So that, even if $M$ differs only by 1 per cent. from what it has been assumed to be, that is, if there is only 1 per cent. of magnetic leakage, the neglected term $\left(15-\frac{\mathrm{M}^{2}}{\mathrm{~L}^{\prime}}\right) \dot{\mathrm{C}}$ becomes of the value

$$
\left\{15-\frac{(1 \cdot 485)^{2}}{\cdot 15}\right\} \dot{\mathrm{C}}
$$

or $0.3 \complement$, or $300 \mathrm{~A} \cos 1000 t$. In fact, the neglected term becomes thirty times as important as the important and certainly hitherto non-neglected term $\mathrm{RC}$ in the equation.

Now in no case is the current truly a sine function of the time, and any departure from this simplest kind of periodic current makes the error of which I speak much greater.*

* As an example, one of many worked out by my students at Finsbury during the last few years: taking the sizes of iron from a certain Mordey transformer which I have occasionally used; assuming permeability constant and no eddy currents in copper or iron; assuming currents to be true sine functions of the time. If $\mathrm{V}$ is voltage at terminals of primary, primary resistance $10 \mathrm{ohms,}$ internal secondary resistance $0.1 \mathrm{ohm}$, outside resistance of secondary in ohms being called $\rho$; self-induction of primary $1 \overline{1}$ secohms, self-induction of secondary 0.15 secohm; assuming $\mathrm{V}$ in volts $=1000 \sin \frac{2 \pi}{\tau} t$, and taking frequency 106 or $\tau=1 \div 106$ second, it is quite easy to calculate to any number of places of decimals 
Of course, any self-induction in the outside part of the secondary circuit will produce the same effect as a leakage in the transformer itself.

The interesting fact to which I wish to draw the attention of members of the Society is this, that however great may be the magnetic leakage, Mr. Blakesley's method is still correct if magnetic permeability is assumed constant during a cycle. Multiplying equation (2) by $\mathrm{C}$ we have

$$
\mathrm{VC}=\mathrm{RC}^{2}-r \frac{\mathrm{M}}{\overline{\mathrm{L}}^{\prime}} \mathrm{CC}^{\prime}+\frac{\mathrm{LL}^{\prime}-\mathrm{M}^{2}}{\mathrm{~L}^{\prime}} \mathrm{C} \dot{\mathrm{C}} . \quad . \quad .
$$

Integrating for the whole periodic time and dividing by

that may be desired, the amplitudes and lags of the primary and secondary currents, and indeed all other magnitudes involved. The graphic method of working is evidently quite out of the question.

My students have for several years made calculations of this kind, obtaining tables of values for various frequencies and amounts of iron in the transformer, and they are exceedingly instructive. Until such tables are compared with actual experimentil results, it seems to me that debates as to the effect of hysteresis consist merely of assertions having no physical basis.

For my present purpose I will give part of two tables calculated by Mr. Eliott, one of my students. Taking the above values :-

1st. If we assume that there is no magnetic leakage. In that case $\mathrm{M}=\sqrt{\mathrm{LL}^{\prime}}=1.5$ secohms. Using this value of $\mathrm{M}$ we get table $\mathrm{I}$.

2 nd. If we assume that there is a little magnetic leakage, say one and one third per cent., or that $M=1 \cdot 48$ secohms. Using this value of $M$ we get Table II.

Now it is perfectly certain that there is some magnetic leakage, always; but it is rather difficult to say just how much there may be. I have here assumed in taking $M=1.48$ instead of 1.50 that $1 \frac{1}{3}$ per cent. of the total induction due to the primary coils does not pass through the secondary coils, and that $1 \frac{1}{3}$ per cent. of the total induction due to the secondary coils does not pass through the primary coils. This number has been taken at random.

The meanings of the letters used at the heads of the various columns are these :-

If

$$
\begin{aligned}
& \mathrm{V}=1000 \sin \frac{2 \pi}{\tau} t, \\
& \mathrm{C}=\mathrm{A} \sin \left(\frac{2 \pi}{\tau} t-\epsilon\right), \\
& \mathrm{I}^{\prime}=\mathrm{A}^{\prime} \sin \left(\frac{2 \pi}{\tau} t-\epsilon^{\prime}\right), \\
& \mathrm{Y}^{\prime}=a^{\prime} \sin \left(\frac{2 \pi}{\tau} t-\epsilon^{\prime}\right)=\rho \mathrm{C}^{\prime}, \\
& \mathrm{P}=\text { average power given to primary, } \\
& \mathrm{P}^{\prime}=\text { average power given out by secondary. } \\
& \text { Percentage efficiency }=100 \mathrm{P}^{\prime} / \mathrm{P} .
\end{aligned}
$$

Evidently $\mathrm{V}^{\prime}$ is the voltage at the terminals of the secondary circuit. Angles of lag are given in degrees. 
this time-that is, taking the average value of every term in (3) it is to be observed that

$$
\frac{1}{\tau} \int_{t}^{\tau+t} \mathrm{C} \dot{\mathrm{C}} \cdot d t=\frac{1}{\tau} \int_{\mathrm{C}_{0}}^{\mathrm{C}_{0}} \mathrm{C} \cdot d \mathrm{C}=0
$$

if $\mathrm{C}_{0}$ is the value of $\mathrm{C}$ at the beginning and end of the period; and hence, as $\frac{\mathrm{M}}{\overline{\mathrm{L}}^{\prime}}=\frac{\mathrm{P}}{\mathrm{S}}$ very nearly,

$$
\text { Average } \mathrm{VC}=\text { average } \mathrm{RC}^{2} \text {-average } r \frac{\mathrm{P}}{\mathrm{S}} \mathrm{CC}_{1} \text {. }
$$

If either $\mathrm{C}$ or $\mathrm{C}^{\prime}$ were the current in a non-inductive circuit, a great error would be introduced by endeavouring to measure the average product by the split dynamometer method; but there is no such error here.

Hence Mr. Blakesley's method is correct, however great may bo the magnetic leakage. It must be remembered, however, that I have neglected eddy currents in the copper and iron; and I assume magnetic permeability to be constant during

Now at full loads on this transformer it is perfectly obvious that currents, lags, and powers are immensely altered by this small amount of leakage which $I$ have introduced as possible. The eurrents are ten times as great, and the lags are utterly different from what they have been supposed to be.

\begin{tabular}{|c|c|c|c|c|c|c|c|c|}
\hline$\rho$. & d. & $\mathbf{A}^{\prime}$. & E. & $\dot{t}^{\prime}$. & P. & $\mathbf{P}^{\prime}$. & Effic. & $a^{\prime}$. \\
\hline$\infty$ & $0 \cdot 1000$ & 0 & 89.9 & 179.9394 & 0850 & 0 & 0 & 100 \\
\hline 99.9 & $U \cdot 1412$ & 0.9991 & 44.97 & $179-9395$ & $50 \cdot 06$ & 49.85 & $99 \cdot 50$ & 9982 \\
\hline $49 \cdot 9$ & $0 \cdot 2232$ & 1.9965 & $26 \cdot 50$ & 179.9395 & $99 \cdot 95$ & $99 \cdot 45$ & 99.49 & $9 y \cdot 61$ \\
\hline $9 \cdot 9$ & 0.9956 & 9.913 & 0.05 & 179.9401 & $497 \cdot 8$ & $486 \cdot 4$ & $97 \cdot 70$ & $y \cdot 14$ \\
\hline $4 \cdot 9$ & 1.963 & $19 \cdot 61$ & 0 & $179.9 \pm 09$ & $981 \cdot 7$ & $942 \cdot 3$ & 95.98 & $96 ;-08$ \\
\hline $0 \cdot 9$ & $9 \cdot 09$ & $90 \cdot 95$ & 0 & 179.9468 & 4545 & 3722 & $31 \cdot 70$ & $81 \cdot 85$ \\
\hline $0 \cdot 4$ & $16 \cdot 67$ & $166 \cdot 6$ & 0 & 1799519 & 8335 & 5501 & $66 \cdot 61$ & $60 ;-6 ; 4$ \\
\hline $0 \cdot 1$ & $33 \cdot 33$ & $333 \cdot 3$ & 0 & $179 \cdot 9610$ & 16667 & 5554 & 33.33 & 3333 \\
\hline 0 & 50 & 500 & 0 & $179 \cdot 9708$ & 25000 & 0 & 0 & (1) \\
\hline
\end{tabular}

TABLE I.-No Magnetic Leakage, or $\mathrm{M}=1 \cdot 5$.

\begin{tabular}{|c|c|c|c|c|c|c|c|c|}
\hline$\rho$. & A. & $A^{\prime}$. & E. & $\epsilon^{\prime}$. & P. & $P^{\prime}$. & Effic. & $a^{\prime}$. \\
\hline & $\cdot 1000$ & & $89 \cdot 9$ & 179.939 & .085 & & 0 & 100 \\
\hline $99 \cdot 9$ & $\cdot 1412$ & 0.9858 & $46 \cdot 4$ & 181.5 & $48 \cdot 61$ & 48.54 & 9970 & $98 \cdot 49$ \\
\hline 499 & 2228 & 1.968 & $29 \cdot 5$ & 182.98 & 96.96 & $96 \cdot 65$ & $99 \cdot 68$ & $95 \cdot 98$ \\
\hline $9 \cdot 9$ & $\begin{array}{r}9627 \\
\end{array}$ & $\begin{array}{r}9458 \\
\end{array}$ & $20 \cdot 4$ & 1948 & $451 \cdot 2$ & 4428 & $98 \cdot 13$ & 93.63 \\
\hline 4.9 & 1741 & $17 \cdot 15$ & 30.4 & 204.85 & $750 \cdot 8$ & 7207 & 96.01 & $84 \cdot 0.5$ \\
\hline 0.9 & $3 \cdot 370$ & $33 \cdot 28$ & $68 \cdot 2$ & $247 \cdot 6$ & 628.4 & $498 \cdot 2$ & $79 \cdot 27$ & $29 \cdot 95$ \\
\hline 0.4 & 3658 & $36 \cdot 11$ & $77 \cdot 6$ & $257 \cdot 33$ & $392 \cdot 8$ & 2607 & $66 \cdot 37$ & $14 \cdot 44$ \\
\hline 0.1 & $\begin{array}{l}3726 \\
3.739\end{array}$ & 36.78 & 83.7 & 26355 & $204 \cdot 4$ & $53 \cdot 75$ & $26 \cdot 29$ & 3678 \\
\hline 0 & & 36.91 & 85.8 & $265 \cdot 7$ & 136.9 & & 0 & 0 \\
\hline
\end{tabular}

Table II.-One and one-third per cent Magnetic Leakage, or $\mathrm{M}=1 \cdot 48$. 
a cycle. If I had time, I could show that in alternating-current calculations there are other very important uses of the fact that $\int_{t}^{\tau+t} x \dot{x} \cdot d t=0$, if $x$ is any periodic function of the time.

\section{Added May 23rd, 1891.}

In the discussion of this paper it was obvious that I had not at sufficient length made known what I meant by magnetic "leakage." It was owing to this, no doubt, that my introduction of the idea of the importance of leakage was looked upon as academic merely. Again, my use of the symbols L, M, and $L^{\prime}$ did not seem to be understood, nor what they had to do with a transformer. It is therefore necessary that I should say more fully, but not more definitely than in the paper, that as $\mathrm{M}$ is always less than $\sqrt{\mathrm{LL}}$ owing to magnetic lenkage, I define leakage as the value of $y$ where

$$
\mathrm{M}=(1-y) \sqrt{\mathrm{LI}^{\prime}} \text {. }
$$

Hence, if $\mathrm{L}=\mathrm{P}^{2} \frac{4 \pi}{10} \frac{a \mu}{\lambda}$ or $\mathrm{P}^{2} m$, say, then $\mathrm{L}^{\prime}=\mathrm{S}^{2} m$ and $\mathrm{M}=\mathrm{PS} m(1-y)$.

Again, the method of treatment to which I object is to state the equations as

$$
\begin{aligned}
& \mathrm{V}=\mathrm{R} \mathrm{C}+\mathrm{P} \frac{d \mathrm{I}}{d t}, \ldots . . \\
& \mathrm{O}=\mathrm{R}^{\prime} \mathrm{C}^{\prime}+\mathrm{S} \frac{d \mathrm{I}}{d t},
\end{aligned}
$$

I affirm that the induction $I$ of equation (1) is a very different thing from the I of equation (2). As the old Maxwell method of writing the equations does not seem to be understood, I wish to make it clear that if I did use the induction I would use $I$ in equation (1) and $I_{8}$ in equation (2), where

$$
\begin{aligned}
& \mathrm{I}_{\mathrm{p}}=\mathrm{P} m \mathrm{C}+\mathrm{S} m(1-y) \mathrm{C}^{\prime}, \\
& \mathrm{I}_{\mathrm{s}}=\mathrm{P} m(1-y) \mathrm{C}+\mathrm{S} m \mathrm{C}^{\prime} .
\end{aligned}
$$

This is assuming that the numbor of ampere-turns which produces the effective induction through the primary is $\mathrm{PC}+\mathrm{S} C^{\prime}(1-y)$; and the number of ampere-turns which produces the effective induction through the secondary is

$$
\mathrm{PC}(1-y)+\mathrm{SC}^{\prime}
$$

In fact, as I stated clearly when reading the paper, $y$ is the 
fractional portion of the field due to primary current which escapes the secondary winding, or it is the fractional portion of the field due to the secondary current which escapes the primary winding. The reasoning is the same even if a small difference be supposed to exist between the $y$ of the first and the $y$ of the second equation; that is, if $M$ is not the same in the two circuits. I submit that in the absence of any prior definition of "leakage" this is simple and reasonable. Dr. Sumpner's "leakage" is a very different thing. He said, let $\mathrm{I}_{\mathrm{p}}=\mathrm{I}_{B}(1+x)$, then $x$ is the magnetic leakage.

Of course, on any reasonable assumption of alterations in $\mu$, the permeability of iron, or on the most reasonable assumption that $\mu$ really is constant during a quickly-performed cycle, Dr. Sumpner's $x$ varies greatly during the cycle. I cannot give a physical meaning to $x$. My "leakage" $y$ does not vary if $\mu$ is constant during a cycle, and I have given a perfectly definite physical meaning to it.

It may be well to add, here, why I think it reasonable to assume $\mu$ constant during a cycle.

1st. I have shown that if there is any leakage, the use of equations (1) and (2) is quite unreasonable.

2nd. If there is any leakage, it is impossible to treat the subject mathematically unless some assumption is made concerning $\mu$.

3rd. It is quite certain that the law of variation of $\mu$ when the cycle is very slowly performed must be quite different from the law when the cycle is very quickly performed, as it always is in practice.

4th. The analogies between magnetic stress and strain and ordinary stress and strain in materials are well established. Now every material exhibits strain hysteresis when slowly loaded and unloaded, and exhibits no hysteresis whatever when the loading and unloading are very quickly performed. Even the most inelastic of materials will transmit a musical note unchanged. Hence for years I have taught my students to look upon magnetic hysteresis as very important when cycles are slowly performed and as unimportant when cycles are very quickly performed. Unless on this assumption, how is it that there is so little heating of the iron of a transformer by hysteresis even when transforming the largest amounts of energy; and such heating as there is must be partly due to eddy currents. I therefore maintain that $\mu$ constant during a cycle (and this means that my "leakage" is constant during a cycle) is the only reasonable assumption that can be made in the present state of our knowledge.

But even if this reasonahle assumption of no hysteresis and 
of the constancy of $\mu$ during a cycle be denied me, and if I must assume the possibility of its being wrong, still $\frac{L L^{\prime}-M^{2}}{L^{\prime}}$ must be more nearly constant than $\mu$; for it is equal to $2 \mathrm{~L} y$. And if $\mu$ increases and therefore $\mathrm{L}$ increases, $y$ will certainly diminish, and if $\mathrm{L}$ diminishes $y$ will certainly increase.

XXVII. The Theory of Magnetism and the Absurdity of Diamagnetic Polarity. By J. PARKer, M.A., Fellow of St. John's College, Cambridge*

THE most unsatisfictory part of the theory of magnetism 1 is that which refers to the so-called diamagnetic bodies. This part of the theory is so beset with absurdities and contradictions that it is necessary to examine it closely and to point out the true explanation of the behaviour of the so-called diamagnetic bodies before we can give the general theory.

I published a short and somewhat premature paper on diamagnetism in the Philosophical Magazine for May 1889. A few weeks afterwards my ideas on the subject had ripened into their present form; but I determined to publish no more about it until after the appearance of my book on 'Elementary Thermodynamics,' which I was then intending to write. Finding, however, that my book was not likely to be finished as soon as I had expected, I published a second short paper on diamagnetism in the Philosophical Magazine for July 1890 , which I thought would be sufficient to explain my ideas until I could give the subject the attention it deserved.

My second paper on diamagnetism was criticised, as I have since found, by Dr. Lodge with a great display of rhetoric in the next number of the Philosophical Magazine; but I was then so occupied that I did not see or hear of the criticism until the following November. When I then came to read it, I did not find anything which required me to modify any of my ideas on the subject in the slightest degree, and I concluded that Dr. Lodge had misunderstood my paper.

It is now proposed to consider the subject carefully and completely, by which means, it is hoped, the disputed points will be settled to the satisfaction of everybody. In so doing, I shall endeavour to prevent all misconception by making my arguments as clear and simple as possible. For this reason I shall employ none but the simplest mathematics,

* Communicated by the Author. 